\title{
The Adapter Protein Grb10 Associates Preferentially with the Insulin Receptor as Compared with the IGF-I Receptor in Mouse Fibroblasts
}

\author{
Luigi Laviola, ${ }^{\star}$ Francesco Giorgino, ${ }^{*}$ Jesse C. Chow, ${ }^{\star}$ Jaime A. Baquero, ${ }^{\star}$ Hans Hansen, ${ }^{*}$ James Ooi, ${ }^{\ddagger}$ Jianwei Zhu, \\ Heimo Riedel, ${ }^{*}$ and Robert J. Smith* \\ *Research Division, Joslin Diabetes Center, Harvard Medical School, Boston, Massachusetts 02215; and ${ }^{\ddagger}$ Howard Hughes Medical \\ Institute, University of Michigan Medical School, Ann Arbor, Michigan 48109
}

\begin{abstract}
To identify receptor-associated proteins that may contribute to the specificity of insulin and IGF-I signaling responses, a mouse embryo library was screened using the yeast two-hybrid system. Multiple receptor-interactive clones encoding the $\mathrm{SH} 2$ domain of the adapter protein Grb10 were isolated. Subsequent cloning of the full-length Grb10 sequence from a mouse fat cDNA library defined a previously unknown Grb10 variant, that appears to be the predominant isoform in mouse tissues. Receptor-deficient $\mathbf{R}$ - cells (fibroblasts from mice with homologous disruption of the IGF-I receptor gene) and transfected $R-$ cells expressing either insulin receptors (R-IR cells) or IGF-I receptors $(R+$ cells) were used to investigate the specificity of Grb10 interaction with the two related receptors. Hormoneactivated insulin receptors in R-IR cells coprecipitated with three species, all recognized as Grb $\mathbf{1 0}$ isoforms by specific Grb10 antibody. Under the same conditions, Grb10 was essentially undetectable in IGF-I receptor immunoprecipitates from stimulated $\mathrm{R}+$ cells. Grb10 association with insulin receptors was maximal at $10 \mathrm{nM}$ insulin stimulation and sustained from 5-10 min after hormone stimulation in R-IR cells. In conclusion, Grb10 interacts preferentially with insulin vs. IGF-I receptors in intact cells and, thus, may have a role in mediating insulin receptor-specific cellular responses. (J. Clin. Invest. 1997. 99:830-837.) Key words: signal transduction - two-hybrid system • receptor tyrosine kinase $\bullet \mathrm{SH} 2$ domain
\end{abstract}

\section{Introduction}

The biological effects of insulin and IGF-I are mediated by distinct but highly homologous cell surface receptors (1-3). Both receptors are comprised of two extracellular $\alpha$ subunits that contain hormone binding sites, and two membrane-spanning $\beta$ subunits that encode an intracellular, hormone-activated ty-

Address correspondence to Robert J. Smith, Research Division, Joslin Diabetes Center, One Joslin Place, Boston, MA 02215. Phone: 617-732-2474; FAX: 617-732-2650; E-mail: smithr@joslab.harvard.edu.

Francesco Giorgino's current address is Istituto di Clinica Medica, Endocrinologia e Malattie Metaboliche, University of Bari School of Medicine, Bari, Italy 70124. Heimo Riedel is a member of the Karmanos Cancer Institute and is currently at the Dept. of Biological Sciences, Wayne State University, Detroit, MI 48202.

Received for publication 22 July 1996 and accepted in revised form 9 December 1996.

J. Clin. Invest.

(C) The American Society for Clinical Investigation, Inc.

0021-9738/97/03/0830/08 \$2.00

Volume 99, Number 5, March 1997, 830-837 rosine kinase. Binding of insulin or IGF-I to its respective receptor stimulates the intrinsic kinase activity and leads to receptor autophosphorylation and receptor interaction with multiple intracellular proteins $(4,5)$, including insulin receptor substrate-1 (IRS-1) $)^{1}(6-9)$, IRS-2 $(10,11)$, the family of proteins designated Shc $(8,9,12)$, and phosphatidylinositol 3-kinase (PI 3-kinase) (13-15). Despite close similarities in the structure of their receptors, insulin and IGF-I have different physiological functions. Insulin acts primarily as a regulator of glucose and body fuel metabolism, while IGF-I functions predominantly in the control of cell growth and differentiation. The distinct effects of the two hormones can be only partially explained by the different tissue distribution of their respective receptors and, therefore, the molecular basis for the biological specificity of insulin and IGF-I remains unclear.

Multiple lines of evidence suggest that insulin and IGF-I receptors themselves have different capacities to activate specific cellular response pathways. When studied in vitro, the two receptor kinases exhibit distinct substrate preferences in their phosphorylation of synthetic artificial peptide substrates (16) or peptides corresponding to the major phosphorylation sites of IRS-I (17). In intact cells, transfected IGF-I receptors were shown to have 10 -fold higher activity in stimulating DNA synthesis than insulin receptors (18), and chimeric IGF-I receptors containing the carboxyl-terminal (COOH-terminal) $\beta$ subunit domain of the insulin receptor were shown to have greater effects on glycogen synthase and mitogen-activated protein (MAP) kinase than native IGF-I receptors (19). Baserga and coworkers have presented evidence that the capacity of the IGF-I receptor to establish and maintain a transformed cellular phenotype depends on a specific amino acid sequence in the $\beta$ subunit which is not present in the insulin receptor (20). It is conceivable that insulin and IGF-I receptors activate distinct cellular responses as a result of different modes of interaction with the same intracellular signaling proteins, or by associating with different signaling mediators.

The yeast two-hybrid system $(21,22)$ is a recently developed technique that can be used to define protein-protein interactions between components of intracellular signaling pathways with high sensitivity. We have previously used a yeast two-hybrid cloning approach to screen a mouse cDNA expression library for insulin receptor interactive proteins and have shown that the src-homology 2 ( $\mathrm{SH} 2)$ domain of the adapter protein Grb10 associates with the tyrosine-phosphorylated insulin receptor $\beta$ subunit (23). Grb10 was originally cloned using a radiolabeled tyrosine phosphorylated fragment of the EGF receptor to screen a NIH-3T3 cell cDNA expression li-

1. Abbreviations used in this paper: aa., amino acid; GM domain, GrbMig domain; IGF-IR, IGF-I receptor; IRS, insulin receptor substrate; MAP, mitogen-activated protein; PH, pleckstrin homology; PI, phosphatidylinositol; RT-PCR, reverse transcriptase-PCR; SH, src homology. 
brary, but its limited interaction with the EGF receptor in comparison with other receptor interactive proteins has led to the suggestion that the EGF receptor may not be the physiological partner for Grb10 (24). Our published findings, together with other reports showing an interaction between human insulin receptors and Grb-IR, an apparent human homologue of the mouse Grb10 $(25,26)$, suggest that the Grb10 protein may function in insulin receptor signaling.

In this study, we describe the screening of a mouse embryo cDNA library for IGF-I receptor interacting proteins with the yeast two-hybrid system. As previously shown for the insulin receptor, the Grb10 SH2 domain represented the most abundant IGF-I receptor interactive species. Since the highly sensitive two-hybrid assay may reveal protein interactions that do not occur physiologically, we then investigated Grb10 interaction with both insulin and IGF-I receptors in intact cells. In mouse fibroblasts transfected with either the insulin receptor or the IGF-I receptor, Grb10 demonstrated a marked preferential association with the insulin receptor and may therefore contribute to the biological specificity of the two hormones.

\section{Methods}

Yeast strains, plasmids, and oligonucleotides. The yeast strains L40 and AMR 70, the yeast expression vectors pVP16 and pBTM116, and 9.5- and 10.5-d mouse embryo cDNA libraries in pVP16 were provided by Stanley Hollenberg (Fred Hutchinson Cancer Research Center, Seattle, WA) and have been previously described $(27,28)$. The LexA fusion plasmid pBTM116 was constructed by Paul Bartel and Stanley Fields (22). Oligonucleotides were obtained from Biosynthesis, Inc. (Lewisville, TX) or the Joslin Diabetes Center core facility. To obtain a LexA-IGF-I receptor hybrid construct, the human IGF-I receptor full length cDNA (2) was digested with ScaI (bp 2983) and BamHI (bp 4155). The obtained 1172-bp fragment was dephosphorylated and ligated to a double stranded DNA fragment obtained by annealing two complementary phosphorylated oligonucleotides: 5' - AATTCGGAGGACTGGGGAATGGAGTGCTGTATGCCTCTGTGAACCCGGAGT-3', and 5'-ACTCCGGGTTCACAGAGGCATACAGCACTCCATTCCCCAGTCCTCCG-3'. This fragment includes basepairs 2944 to 2982 of the IGF-I receptor sequence, the coding sequence of two glycines in frame with the receptor to add flexibility to the fusion junction, and an EcoRI restriction site to enable subcloning of the construct into the yeast vector pBTM116. The IGF-I receptor extended fragment was then ligated into the EcoRI-BamHI site of pBTM116. The resulting construct, containing the complete intracellular portion of the IGF-I receptor $\beta$ subunit including the stop codon (bp 2944 to 4155) fused in frame with the LexA DNA binding domain coding sequence, was verified by sequencing with the dideoxy method using the Sequenase kit (Amersham Life Science, Inc., Arlington Heights, IL).

Two-hybrid screening. The L40 yeast strain was transformed with pBTM116 containing the fused LexA-IGF-I receptor coding sequence by the lithium acetate protocol $(29,30)$. After growth in tryptophan-deficient medium, L40/pBTM116/IGF-I receptor yeast cells were transformed with a pool of pVP16/9.5-d and pVP16/10.5-d mouse embryo cDNA libraries. Transformation with $500 \mu \mathrm{g}$ of library plasmid DNA yielded $\sim 12 \times 10^{6}$ primary transformants, as confirmed by colony growth in tryptophan- and leucine-deficient medium. The yeast were subsequently grown in tryptophan- and leucinedeficient liquid medium for $16 \mathrm{~h}$ to allow for the expression and formation of the transactivating LexA/VP16 complex, and a fraction of the yeast suspension (corresponding to $\sim 4 \times 10^{6}$ primary transformants) was plated on tryptophan-, leucine-, and histidine-deficient plates. Library clones showing activation of both reporter genes (HIS3 for histidine selection and $L a c Z$ for $\beta$ galactosidase activity) were tested in the two-hybrid system for specificity of association with the IGF-I receptor using a LexA-lamin construct as a negative control. Plasmids from library clones were subsequently isolated from the yeast, transferred to Escherichia coli, and sequenced with the Sequenase kit (Amersham Life Science, Inc.) or on a Automatic DNA Sequencer (373; Applied Biosystems, Inc., Foster City, CA). Sequence similarities were sought in GenBank using the GCG program Fasta.

cDNA library screening. Approximately $10^{6}$ plaques from a mouse fat cDNA library in lambda GT11 (Clontech Laboratories, Inc., Palo Alto, CA) were screened with standard techniques using either clone 1.34 obtained from the two-hybrid screening and corresponding to the Grb10 SH2 domain, or a XmnI/HaeII restriction fragment of Grb10 as DNA probes. Positive clones were purified with the LambdaQuick kit (BIO 101, Inc., Vista, CA), subcloned in pBluescript (Stratagene, La Jolla, CA) or pGEM (Promega Corp., Madison, WI), and both strands were sequenced using custom synthetic oligonucleotide primers.

Reverse transcriptase-polymerase chain reaction (RT-PCR). Total RNA was extracted from tissues by the acid guanidinium thiocyanate/phenol/chloroform method (31), and digested with DNase. Single stranded cDNA was synthesized with the Superscript kit (Gibco BRL, Gaithersburg, MD) using $5 \mu \mathrm{g}$ of total RNA. The resulting cDNA was amplified using the sense primer 5'-ACCAGCAGTTAAGAACTGCATC-3', and the antisense primer 5'-CAGTGTCGGTTGGACACTGGTTC-3'. PCR products were subcloned into the pCR II vector (Invitrogen Corp., San Diego, CA) and sequenced.

Cell lines. All cell lines were provided by Dr. Renato Baserga (Jefferson Cancer Center, Thomas Jefferson University, Philadelphia, PA). R- cells $(32,33)$ are a 3T3-like fibroblast cell line established from mouse embryos with a targeted disruption of the IGF-I receptor gene $(34,35)$. The $\mathrm{R}+$ cells represent $\mathrm{R}-$ cells stably transfected with the human IGF-I receptor cDNA $(33,36)$, and R-IR cells are $\mathrm{R}-$ cells overexpressing the human insulin receptor (20).

Immunoprecipitation and immunoblotting. Cell monolayers at $70-80 \%$ confluency were placed in medium containing $0.5 \%$ BSA for $16-18 \mathrm{~h}$ and then incubated for the indicated times at $37^{\circ} \mathrm{C}$ in the presence or absence of IGF-I ( $\mathrm{R}-$ and $\mathrm{R}+$ cells) or insulin $(\mathrm{R}-$ and $\mathrm{R}-\mathrm{IR}$ cells). Cells were then washed with ice-cold $20 \mathrm{mM}$ Tris-HCl, $\mathrm{pH}$ 7.6, containing $137 \mathrm{mM} \mathrm{NaCl}, 1 \mathrm{mM} \mathrm{MgCl}_{2}, 1 \mathrm{mM} \mathrm{CaCl}_{2}$, and 0.1 $\mathrm{mM}$ sodium orthovanadate (buffer A), and solubilized for $45 \mathrm{~min}$ at $4{ }^{\circ} \mathrm{C}$ in buffer A containing $1 \%$ Nonidet P-40, $10 \%$ glycerol, $2 \mathrm{mM}$ EDTA, $2 \mathrm{mM}$ PMSF, $2 \mathrm{mM}$ sodium orthovanadate, $10 \mathrm{mM}$ sodium pyrophosphate, $10 \mathrm{mM}$ sodium fluoride, and $8 \mu \mathrm{g} / \mathrm{ml}$ leupeptin (lysis buffer). Particulate material was removed by centrifugation at $15,000 \mathrm{~g}$ for $5 \mathrm{~min}$ at $4^{\circ} \mathrm{C}$, the supernatants were collected and protein concentrations were determined with a Bradford dye binding assay kit (BioRad Laboratories, Hercules, CA). Equal amounts of cell protein in lysis buffer were incubated at $4^{\circ} \mathrm{C}$ for $2 \mathrm{~h}$ with polyclonal anti-Grb10 antibody 309 (24) (1:100 dilution), or for $1 \mathrm{~h}$ with monoclonal antiIGF-I receptor antibody ( $\alpha$ IR3 at 1:200 dilution, from Steve Jacobs, Burroughs Wellcome Co., Research Triangle Park, NC, 17-69 at 1:200 dilution or 24-31 at 1:200 dilution, from Kenneth Siddle, University of Cambridge, Addenbrooke's Hospital, United Kingdom) or antiinsulin receptor antibody (83-7 at 1:500 dilution from Kenneth Siddle). Rabbit anti-mouse IgG (Pierce Chemical Co., Rockford, IL) was added for $1 \mathrm{~h}$ at $4^{\circ} \mathrm{C}$, the antibodies were adsorbed to protein $\mathrm{A}$ Sepharose beads (Pharmacia Biotech, Inc., Piscataway, NJ) for $1 \mathrm{~h}$ at $4^{\circ} \mathrm{C}$, and the resulting immunocomplexes were washed three times at $4^{\circ} \mathrm{C}$ by centrifugation and resuspension in buffer containing $10 \mathrm{mM}$ Tris- $\mathrm{HCl}, \mathrm{pH} 7.8,150 \mathrm{mM} \mathrm{NaCl}, 1 \%$ Nonidet P-40, $1 \mathrm{mM}$ sodium orthovanadate, and $1 \mathrm{mM}$ PMSF. These pellets plus additional cell lysates not treated with antibodies were boiled in Laemmli buffer with $100 \mathrm{mM}$ dithiothreitol for $5 \mathrm{~min}$. Proteins were separated by SDSPAGE on $8.5 \%$ gels and blotted onto nitrocellulose membranes (Schleicher \& Schuell, Inc., Keene, NH). The blots were incubated in $10 \mathrm{mM}$ Tris- $\mathrm{HCl}, \mathrm{pH} 7.8,0.9 \% \mathrm{NaCl}$, and $0.01 \%$ sodium azide (TNA buffer) containing $5 \%$ BSA and $0.05 \%$ Nonidet $\mathrm{P}-40$ for $2 \mathrm{~h}$ at $37^{\circ} \mathrm{C}$ and subsequently incubated for $16 \mathrm{~h}$ at $4^{\circ} \mathrm{C}$ with anti-Grb10 antibody 
309 (24) (1:300 dilution) or antiphosphotyrosine antibody $(2 \mu \mathrm{g} / \mathrm{ml})$ (37). After washing twice with TNA buffer plus $0.05 \%$ NP- 40 , the membranes were incubated with ${ }^{125} \mathrm{I}$ protein $\mathrm{A}(0.2 \mu \mathrm{Ci} / \mathrm{ml})$ in TNA buffer containing $5 \%$ BSA and $0.05 \%$ Nonidet P-40 for $1 \mathrm{~h}$ at room temperature, and specific protein bands were detected using a phosphorimaging system (Molecular Dynamics, Sunnyvale, CA).

\section{Results}

Two-hybrid cloning of IGF-I receptor interactive proteins. We have previously reported the identification of the $\mathrm{SH} 2$ domain of the Grb10 adapter protein in a yeast two-hybrid screening of mouse embryo cDNA libraries using the insulin receptor $\beta$ subunit as a probe (23). To identify IGF-I receptor-associated proteins, and to investigate the specificity of substrate interaction in insulin and IGF-I signaling pathways, we performed similar screening of the same mouse embryo libraries for IGF-I receptor interactive proteins. The yeast vector pBTM116 expressing the full cytoplasmic domain of the IGF-I receptor (aa. 937-1337) as a fusion protein linked to the $\mathrm{COOH}$ terminus of the DNA binding domain of the transcription factor LexA was introduced into the yeast reporter strain L40. Yeast expressing the pLexA-IGF-I receptor fusion protein were then transformed with a library of mouse embryo cDNA fragments expressed as fusions to the VP16 acidic activation domain. In this modified two-hybrid system $(27,28)$, positive clones are identified by detecting the activation of two reporter genes, HIS3 and $L a c Z$, inserted into the L40 yeast genome with multiple LexA upstream activating sequences. Approximately $4 \times 10^{6}$ yeast transformants were screened, 300 clones were selected based on growth in histidine-deficient medium, and 141 of these clones displayed a strong reaction in a $\beta$ galactosidase color assay. These double positive clones were then cured of the pLexA-IGF-I receptor plasmid by growth in tryptophansupplemented medium, thus eliminating the selective pressure to retain the pBTM116 plasmid. The 141 positive clones, confirmed to contain only the library pVP16 plasmid, were retested in the $\beta$ galactosidase assay, and three clones were eliminated because of blue color formation in the absence of two-hybrid complex formation, indicating nonspecific activation of the reporter system. The interaction of the remaining clones with the IGF-I receptor was then retested by mating the L40 yeast containing the library clones with another yeast strain, AMR 70, containing the IGF-I receptor plasmid or LexA-lamin as a negative control sequence. The specific interaction of 70 clones with the IGF-I receptor was confirmed by this method. Duplicate sequences were identified by DNA sequence analysis, and a total of 27 independent clones ultimately were defined.

The majority of the isolated clones (10 of 27) encoded the $\mathrm{SH} 2$ domain from the $\mathrm{COOH}$-terminal region of the adapter protein Grb10 (24) fused to VP16. The distinct Grb10 clones included various portions of the Grb10 pleckstrin homology (PH) domain and the entire $\mathrm{SH} 2$ domain extending through the putative stop codon. Eight of the remaining clones coded for the $\mathrm{COOH}$-terminal $\mathrm{SH} 2$ domains of three isoforms of the regulatory subunit of PI 3-kinase: p85 $\alpha$ (1 clone), p85 $\beta$ ( 5 clones), and the recently described p55 $^{\mathrm{PIK}}$ (38) (two clones). Among the remaining independent clones, four encoded fragments containing the $\mathrm{SH} 2$ domain of distinct nonreceptor tyrosine kinases: csk, fyn, src, srm. Two clones represented novel sequences, with no significant homology in the GenBank search, and three were complementary strand cloning artifacts.
A

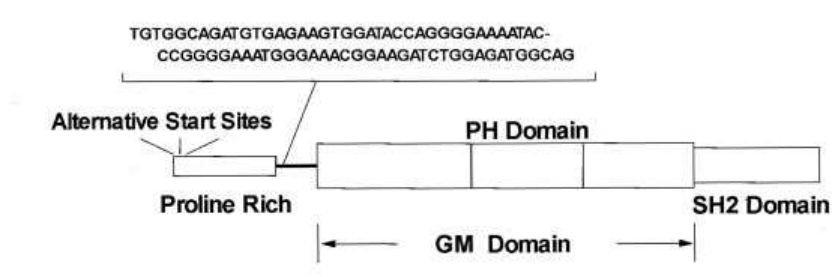

B

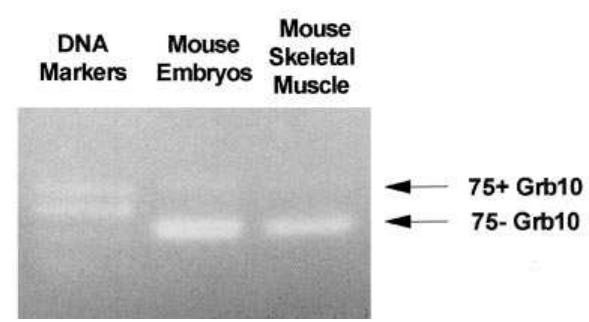

Figure 1. (A) Schematic representation of Grb10 cDNA sequence. The proline-rich, $\mathrm{PH}, \mathrm{GM}$, and $\mathrm{SH} 2$ domains are noted. The sequence of the alternatively spliced 75-bp fragment is indicated. (B) Identification of Grb10 splice variants. Total RNA from mouse embryos or skeletal muscle was reverse transcribed and amplified with DNA primers flanking the 75-bp divergent region, as described in Methods. PCR products were resolved by electrophoresis on a $3 \%$ agarose gel and visualized by ultraviolet transillumination. The results shown are representative of those obtained in three separate experiments.

Characterization of the Grb10 Sequence. Northern blotting using a Grb10 cDNA probe encoding the $\mathrm{SH} 2$ domain and a portion of the $\mathrm{PH}$ domain demonstrated a single abundant $5.5-\mathrm{kb}$ transcript in multiple mouse tissues, consistent with previously reported results (24). Grb10 mRNA levels were low in liver, but abundant in peripheral insulin target tissues, including skeletal muscle, heart, and adipose tissue (data not shown). To examine the full-length sequence, $\sim 10^{6}$ plaques from a mouse fat cDNA lambda GT11 library were screened for hybridization with cDNA probes obtained from the two-hybrid derived clones. Six overlapping clones were isolated that defined a unique open reading frame identical in sequence to the initially cloned Grb10, except for the absence of a 75-bp segment located between the proline-rich region and the PH domain, corresponding to aa. 117-141 in the initially cloned Grb10 (Fig. 1 A) (24). Four independent library clones encompassed this divergent region, and all four encoded the same shorter form of Grb10. The sequence of the 75-bp insertion ends with $\mathrm{AG}$, which represents the required consensus sequence for a $3^{\prime}$ intron-exon splice site (39). Domains present in both forms of Grb10 include three potential translation initiation codons, an amino-terminal proline-rich region, a central domain homologous to Grb7 and Mig10 (designated the GM domain) (40), a PH domain within the GM domain, and the $\mathrm{COOH}$-terminal $\mathrm{SH} 2$ domain identified in the two-hybrid screening.

To examine the expression of the two alternative Grb10 sequences in mouse tissues, an RT-PCR assay was developed using primers that flanked the divergent region and contained sequence common to both Grb10 mRNA variants. Using mouse skeletal muscle or total embryo RNA as template, two PCR fragments appropriate in size for inclusion and exclusion of the 


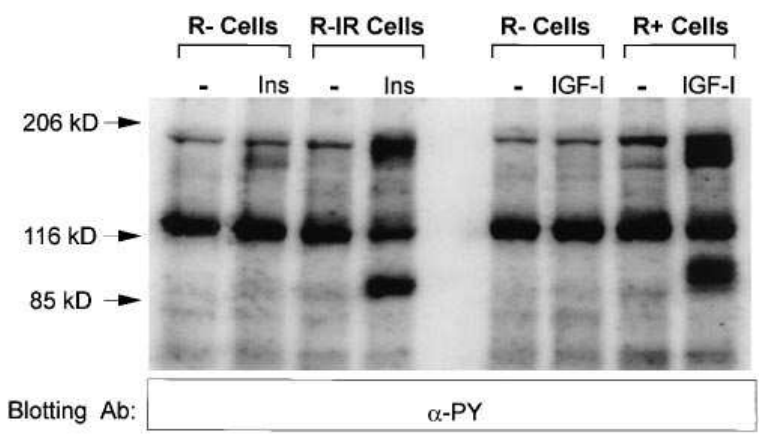

Figure 2. Protein tyrosine phosphorylation in the $\mathrm{R}-$ cell system. $\mathrm{R}-$, $\mathrm{R}-\mathrm{IR}$, and $\mathrm{R}+$ cells in $0.5 \% \mathrm{BSA}$ were incubated for $10 \mathrm{~min}$ at $37^{\circ} \mathrm{C}$ in the absence or presence of $100 \mathrm{nM}$ insulin $(\mathrm{R}-$ and $\mathrm{R}-\mathrm{IR}$ cells) or $100 \mathrm{nM}$ IGF-I (R- and R+ cells). Total cell lysates were separated by SDS-PAGE on an $8.5 \%$ gel, transferred to nitrocellulose, and analyzed by antiphosphotyrosine immunoblotting and detection with ${ }^{125}$ I-labeled protein A, as described in Methods. Ins, insulin; $P Y$, phosphotyrosine. The results shown are representative of those obtained in two independent experiments.

75-bp segment were amplified (Fig. $1 B$ ). The identities of the two bands as Grb10 with or without the 75-bp insert were confirmed by subcloning and sequencing. Both variants could therefore be detected in the analyzed tissues, although the shorter form cloned in this study appeared to be much more abundant, as evident in Fig. $1 B$.

Insulin and IGF-I receptor interactions with Grb10 in intact cells. Previous studies have demonstrated three Grb10 antibody interactive proteins in NIH-3T3 cells with apparent $M_{\mathrm{r}}$ from 65 to $85 \mathrm{kD}$ (24). These bands are thought to represent distinct protein isoforms of Grb10 derived from alternative splicing and/or the alternative translation initiation codons. To verify in intact cells the detected association of Grb10 with the insulin and the IGF-I receptor, we used the $\mathrm{R}$ - fibroblast cell line, which was derived from mice with targeted disruption of the IGF-I receptor gene $(34,35)$. These cells have no IGF-I receptors and very low levels of endogenous insulin receptor $(\sim 5,000$ receptors/cell) $(32,33)$. For studies on Grb10/receptor interactions, $\mathrm{R}-$ cells were obtained that were stably transfected with either the human insulin receptor (R-IR cells, expressing $0.5 \times 10^{6}$ receptors/cell), or the human IGF-I receptor $\left(\mathrm{R}+\right.$ cells, expressing $1 \times 10^{6}$ receptors/cell) $(20,36)$. Therefore, distinct modes of association of Grb10 with insulin receptors compared with IGF-I receptors could be investigated in the same cellular background.

To study the pattern of hormone-stimulated tyrosine phosphorylation in the $\mathrm{R}-$ cell system, lysates from $\mathrm{R}-$, R-IR and $\mathrm{R}+$ cells were analyzed by antiphosphotyrosine antibody immunoblotting. In lysates from untransfected $\mathrm{R}-$ cells stimulated with either hormone, phosphorylated insulin receptors or IGF-I receptors were not detectable (Fig. 2). When we analyzed receptor-transfected cell lines, tyrosine phosphorylation of a molecular species of $\sim 95 \mathrm{kD}$, corresponding to the insulin receptor $\beta$ subunit, was evident in lysates from insulin-stimulated R-IR cells (Fig. 2). Similarly, an IGF-I-stimulated tyrosine phosphorylated protein with slightly lower gel mobility, corresponding to the IGF-I receptor $\beta$ subunit, was evident in $\mathrm{R}+$ cell lysates. In both the $\mathrm{R}-\mathrm{IR}$ and $\mathrm{R}+$ cell lines, hormonestimulated tyrosine phosphorylation of one or more proteins in the $180-190 \mathrm{kD}$ range also was observed. These bands likely

B
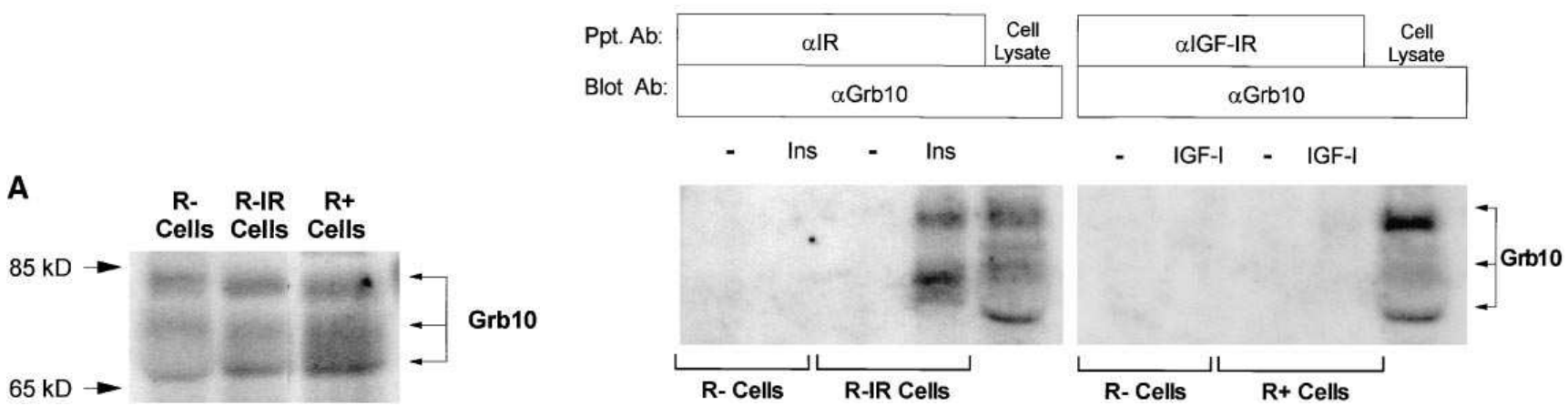

Figure 3. (A) Grb10 protein expression in the $\mathrm{R}$ - cell system. Lysates from $\mathrm{R}-$, $\mathrm{R}-\mathrm{IR}$, and $\mathrm{R}+$ cells were separated by SDS-PAGE on an $8.5 \%$ gel, transferred to nitrocellulose, and analyzed by immunoblotting with anti-Grb10 antibody 309 and detection with ${ }^{125}$ I-labeled protein A, as described in Methods. The three major Grb10 isoforms are indicated. (B) Grb10 protein coprecipitation with insulin receptors and IGF-I receptors. $\mathrm{R}-, \mathrm{R}-\mathrm{IR}$, and $\mathrm{R}+$ cells in $0.5 \% \mathrm{BSA}$ were incubated for $10 \mathrm{~min}$ at $37^{\circ} \mathrm{C}$ in the absence or presence of $100 \mathrm{nM}$ insulin ( $\mathrm{R}-$ and R-IR cells) or $100 \mathrm{nM}$ IGF-I (R - and R+ cells).

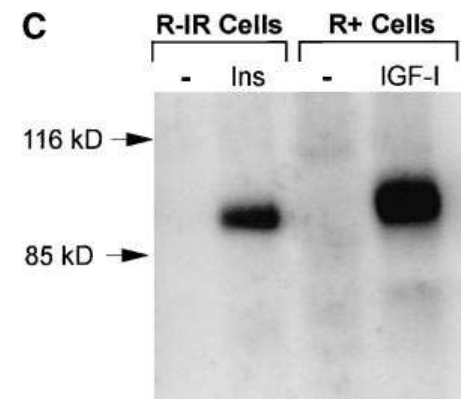
Total cell lysates were either left untreated (right lane in each blot) or subjected to immunoprecipitation with anti-insulin receptor antibody ( $\mathrm{R}$ - and R-IR cells) or anti-IGF-I receptor antibody $(\mathrm{R}-$ and $\mathrm{R}+$ cells). Cell lysates, insulin receptor, and IGF-I receptor immunoprecipitates were separated by SDSPAGE on $8.5 \%$ gels, transferred to nitrocellulose, and analyzed by immunoblotting with anti-Grb10 antibody 309 and detection with ${ }^{125}$ I-labeled protein A, as described in Methods. The three major Grb10 isoforms are indicated. $(C)$ Phosphorylated insulin and IGF-I receptors in the R-cell system. R-IR and $\mathrm{R}+$ cells were treated as described for $B$. Insulin and IGF-I receptor immunoprecipitates were separated by SDS-PAGE on an $8.5 \%$ gel, transferred to nitrocellulose, and analyzed by immunoblotting with phosphotyrosine antibody and detection with ${ }^{125}$ I-labeled protein A. Ppt. Ab, precipitating antibody; Blot $A b$, blotting antibody; $I R$, insulin receptor; $I G F-I R$, IGF-I receptor; Ins, insulin. The results shown are representative of those obtained in three independent experiments. 
represent the IRS proteins $(10,41)$, indicating that the transfected insulin and IGF-I receptors are able to interact with their physiological substrates. A low level of IRS activation was detectable in lysates from insulin-stimulated R- cells (Fig. 2 , lane 2), which likely results from activation of the small number of endogenous insulin receptors in these cells.

To assess the interaction of Grb10 with the insulin receptor, lysates were prepared from unstimulated or insulin-stimulated R-IR cells, and equal amounts of solubilized protein were subjected to immunoprecipitation with an anti-insulin receptor monoclonal antibody. Precipitates were solubilized in Laemmli buffer, separated by SDS-PAGE, and analyzed by immunoblotting with anti-Grb10 antibody 309 (24). In direct immunoblots of solubilized total cell proteins, Grb10 antibody identified three major protein species ranging between 65 and $85 \mathrm{kD}$ in lysates from both R- and R-IR cells, corresponding to the previously identified Grb10 protein isoforms present in other cell types (24) (Fig. $3 A$ ). The three Grb10 proteins also were detected in insulin-receptor immunoprecipitates from insulin-stimulated R-IR cells (Fig. 3 B, left). These Grb10 protein isoforms were not detectable in insulin receptor antibody immunoprecipitates from unstimulated R-IR cells, and were also absent in similar immunoprecipitates from basal or stimulated $\mathrm{R}$ - cells (Fig. 3 B, left). Thus, it can be concluded that endogenous Grb10 proteins specifically coprecipitate with insulin receptors activated by insulin stimulation.

The $\mathrm{R}+$ cells were used in similar coprecipitation experiments to examine the interaction of the Grb10 proteins with the IGF-I receptor. The $\mathrm{R}+$ cells express similar levels of Grb10 protein isoforms in comparison with $\mathrm{R}-$ and $\mathrm{R}-\mathrm{IR}$ cells, as shown in Fig. $3 \mathrm{~A}$. However, when $\mathrm{R}+$ cell lysates were subjected to immunoprecipitation with anti-IGF-I receptor antibody $\alpha$ IR3 and subsequent immunoblotting with antiGrb10 antibody, Grb10 protein isoforms were not clearly detectable in IGF-I receptor immunoprecipitates from basal or IGF-I-stimulated cells (Fig. 3 B, right). Similar results were obtained when $\mathrm{R}+$ cell lysates were immunoprecipitated with two additional anti-IGF receptor antibodies, 17-69 and 24-31, ruling out the possibility that the decreased affinity of Grb10 interaction with IGF-I receptors was due to a structural modification induced by the specific antibody used for precipitation. In receptor immunoprecipitates from $\mathrm{R}+$ and $\mathrm{R}-\mathrm{IR}$ cells similar to those shown in Fig. $3 \mathrm{~B}$, a greater amount of phosphorylated IGF-I receptors vs insulin receptors, respectively, was measurable by phosphotyrosine antibody immunoblotting (Fig. $3 C$ ). Thus, in spite of the similar abundance of endogenous Grb10 proteins in R-IR and $\mathrm{R}+$ cells and greater amounts of immunoprecipitated tyrosine phosphorylated IGF-I receptors in R+ cells, Grb10 was selectively coprecipitated with insulin receptors. Grb10 preferential association with the insulin receptor was subsequently confirmed by immunoprecipitating lysates from hormone-stimulated R-IR and R+ cells with anti-Grb10 antibody and analyzing pelleted proteins by phosphotyrosine antibody immunoblotting. A much greater amount of phosphorylated insulin receptors was detectable in Grb10 antibody precipitates from R-IR cells compared to IGF-I receptors from $\mathrm{R}+$ cell lysates (Fig. 4).

When Grb10 association with insulin receptors and IGF-I receptors was examined at multiple time points after hormone stimulation (Fig. $5 \mathrm{~A}$ ), maximum Grb10 coprecipitation with the insulin receptor in R-IR cell lysates was observed at 5 and 10 min after insulin stimulation, with decreased association ev-

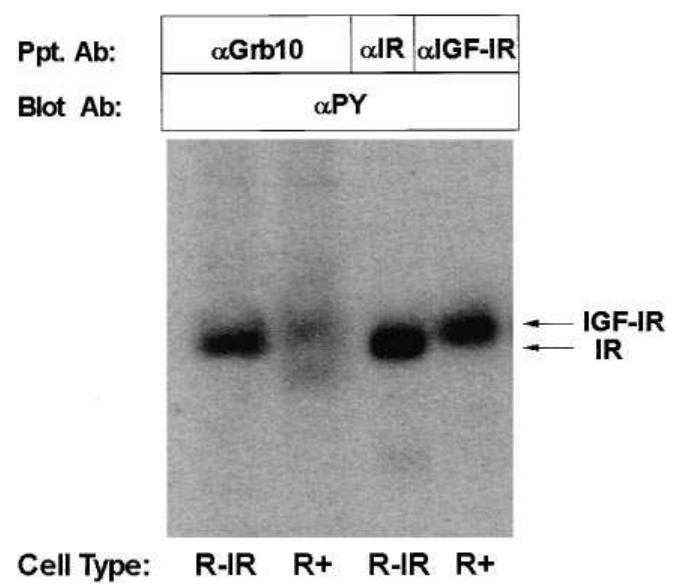

Figure 4. Insulin and IGF-I receptor coprecipitation with Grb10. $\mathrm{R}-\mathrm{IR}$ and $\mathrm{R}+$ cells in $0.5 \% \mathrm{BSA}$ were incubated at $37^{\circ} \mathrm{C}$ for $10 \mathrm{~min}$ in the presence of $100 \mathrm{nM}$ insulin (R-IR cells) or $100 \mathrm{nM}$ IGF-I (R+ cells). Total cell lysates were subjected to immunoprecipitation with anti-Grb10 antibody 309, anti-insulin receptor antibody (R-IR cells), or anti-IGF-I receptor antibody $(\mathrm{R}+$ cells). Grb10, insulin receptor and IGF-I receptor immunoprecipitates were separated by SDSPAGE on $8.5 \%$ gels, transferred to nitrocellulose, and analyzed by immunoblotting with phosphotyrosine antibody 309 and detection with ${ }^{125} \mathrm{I}$-labeled protein A, as described in Methods. Ppt. Ab, precipitating antibody; Blot $A b$, blotting antibody; $I R$, insulin receptor; $I G F$ $I R$, IGF-I receptor. The results shown are representative of three separate experiments.

ident after $20 \mathrm{~min}$, whereas very low to undetectable levels of Grb10 were present in IGF-I receptor immunoprecipitates from $\mathrm{R}+$ cells at all time points (Fig. $5 \mathrm{~A}$ ). The association of Grb10 with the insulin receptor was dose dependent, with detectable Grb10 in receptor precipitates from R-IR cells treated with $1 \mathrm{nM}$ insulin and maximum Grb10-receptor coprecipitation with $10 \mathrm{nM}$ insulin (Fig. 5 B). By contrast, IGF-I receptorassociated Grb10 was low to undetectable at IGF-I concentrations up to $100 \mathrm{nM}$. When much larger amounts of protein from $\mathrm{R}+$ cells were analyzed, a small amount of Grb10 protein coprecipitated with the IGF-I receptor was evident (data not shown). From these experiments, we conclude that Grb10 interacts preferentially with insulin receptors as compared to IGF-I receptors in the $\mathrm{R}-$ cell system.

\section{Discussion}

Grb10 is a protein of yet undefined function with the structural features of an adapter protein, containing $\mathrm{SH} 2, \mathrm{PH}$, and proline-rich (presumed SH3 domain binding) domains. Grb10 was originally isolated from an NIH-3T3 cell expression library through its ability to interact with the tyrosine phosphorylated $\mathrm{COOH}$ terminus of the EGF receptor (24). Although GST fusion proteins containing the Grb10 SH2 domain were subsequently shown to precipitate the EGF receptor from cell lysates, an interaction between the EGF receptor and the endogenous Grb10 protein in intact cells overexpressing EGF receptors could not be demonstrated (24). In another report Grb10 was identified as a protein interactive with the Ret receptor tyrosine kinase by yeast two-hybrid screening (42). A GST-Grb10 fusion protein was shown to interact with Ret in 


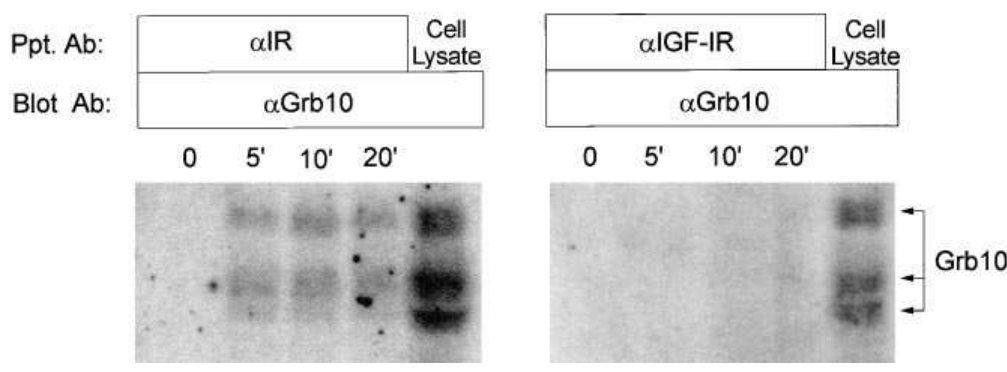

B

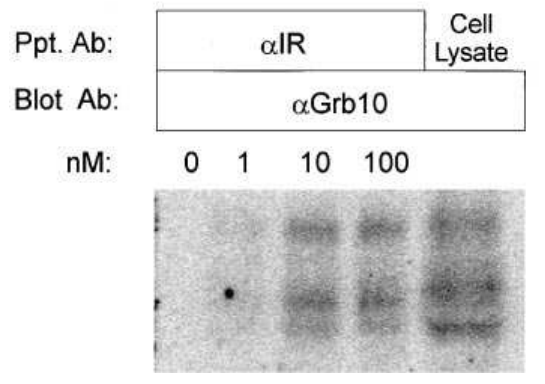

IGF-I- stimulated R+ Cells

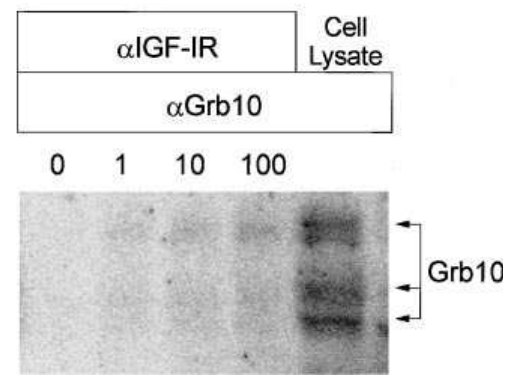

Figure 5. Time-course and dose-response of Grb10 association with insulin receptors and IGF-I receptors in the R - cell system. R-IR and R+ cells in $0.5 \% \mathrm{BSA}$ were incubated at $37^{\circ} \mathrm{C}$ for the indicated times in the absence or presence of $100 \mathrm{nM}$ insulin $(R$-IR cells $)$ or $100 \mathrm{nM}$ IGF-I $(R+$ cells $)(A)$, or incubated at $37^{\circ} \mathrm{C}$ for $10 \mathrm{~min}$ with the indicated hormone concentrations $(B)$. Total cell lysates were either left untreated (right lane in each blot) or subjected to immunoprecipitation with anti-insulin receptor antibody $(R$-IR cells) or anti-IGF-I receptor antibody $(R+$ cells $)$. Cell lysates, insulin receptor and IGFI-receptor immunoprecipitates were separated by SDS-PAGE on $8.5 \%$ gels, transferred to nitrocellulose, and analyzed by immunoblotting with antiGrb10 antibody 309 and detection with ${ }^{125}$ I-labeled protein A, as described in Methods. Ppt. Ab, precipitating antibody; Blot $A b$, blotting antibody; $I R$, insulin receptor; $I G F-I R$, IGF-I receptor. The results shown are representative of those obtained in three separate experiments. vitro, and Grb10 coprecipitated with Ret in extracts from cells overexpressing both proteins. However, significant association of endogenous Grb10 proteins with the Ret receptor has not been demonstrated. We have isolated Grb10 as a protein interacting with the insulin receptor (23) and, in the present study, with the IGF-I receptor using yeast two-hybrid cloning. The findings from these various studies suggest that Grb10 may be a signaling mediator shared by multiple tyrosine kinase receptors, as occurs with PI 3-kinase and Shc. Alternatively, Grb10 interactions with receptor proteins may have greater specificity than is evident with highly sensitive methods, such as yeast two-hybrid system cloning and in vitro fusion protein studies.

In the present study, the IGF-I receptor was shown to interact with multiple proteins in the two-hybrid system, including Grb10, three isoforms of the PI 3-kinase regulatory subunit (p85 $\alpha, \mathrm{p} 85 \beta$, and $\mathrm{p} 55^{\mathrm{PIK}}$ ), and several nonreceptor tyrosine kinases (src, fyn, srm, and csk). All of these proteins contain SH2 domains, and p85 has previously been shown to have the capacity to interact with the IGF-I receptor (15). We further investigated the interaction of Grb10 with IGF-I and insulin receptors in intact cells, since Grb10 was the most abundant species isolated by two-hybrid screening of the same libraries with the complete intracellular region of either of these receptors. For this purpose, we used $\mathrm{R}$ - cells transfected with the insulin receptor ( $\mathrm{R}-\mathrm{IR}$ cells) or the IGF-I receptor $(\mathrm{R}+$ cells) $(20,35)$. The parent $\mathrm{R}-$ cell line has no IGF-I receptors as a consequence of targeted disruption of the IGF-I receptor gene and a low number of endogenous insulin receptors $(\sim 5,000$ receptors/cell). The signaling characteristics of the transfected insulin or IGF-I receptors can therefore be investigated with essentially no background of insulin receptor/IGF-I receptor hybrids, which may otherwise mask the properties of the individual receptors $(43,44)$.

In the R- cell system, Grb10 exhibited marked preferential association with the insulin receptor in comparison with the IGF-I receptor. Interaction of Grb10 with IGF-I receptors as well as insulin receptors in the two-hybrid system may reflect the high sensitivity of this method, which detects interactions between two overexpressed fusion proteins (45). As additional possibilities, posttranslational modifications of Grb10 and/or the receptor essential for interaction specificity may not occur in the yeast cytoplasm, or the pattern of Grb10 association with the receptors may be modulated by molecules that are not present in the yeast cell. Since clones containing only the $\mathrm{SH} 2$ domain of Grb10 were isolated in the two-hybrid screening, it is also possible that the full-length Grb10 protein may exhibit a higher degree of specificity for the insulin receptor compared with the IGF-I receptor in its native conformation within the cell. Alternatively, additional regions of the full-length Grb10 protein besides the SH2 domain may contribute to the preferential interaction with the insulin receptor.

It has previously been suggested that distinct cellular responses to insulin and IGF-I may result from structural features unique to the insulin and IGF-I receptors and/or to differences in early steps of their signal transduction pathways (16-19). In a recent study proposing Crk II as a novel IGF-I receptor substrate, it was shown that insulin is less effective than IGF-I in promoting Crk phosphorylation, although the formation of a stable complex between Crk and IGF-I or insulin receptors in intact cells was not demonstrated (46). Therefore, Grb10 represents the first example of a protein that forms a stable intermolecular complex preferentially with one of these two related receptors. In studies with a GST-fusion protein containing the Grb10 SH2 domain, we have previously shown that the formation of an intermolecular conjugate with the insulin receptor requires the presence of the last 43 amino acids in the $\mathrm{COOH}$ terminus of the receptor (23). We further showed that a peptide containing sequence corresponding to the YXXM motif at tyrosine 1322 in the receptor $\mathrm{COOH}$ terminus had the highest affinity for Grb10 SH2 domain binding, thus implicating this specific sequence in the Grb10-receptor interaction. This is of interest in regard to earlier evidence that 
insulin and IGF-I receptor $\mathrm{COOH}$-terminal regions may be important in defining the relative intensities of metabolic vs mitogenic signaling by these two receptors $(19,47,48)$. The primary structures of the two receptors are highly divergent in this region ( $45 \%$ homology in the $\mathrm{COOH}$ terminus vs $84 \%$ in the kinase domain), and thus specific domains may reside in the insulin receptor $\mathrm{COOH}$ terminus that are responsible for its preferential interaction with the full-length Grb10 protein. It is possible that structural features unique to the insulin receptor may establish a receptor conformation that favors its interaction with Grb10. Alternatively, another molecule could bind specifically to the IGF-I receptor $\mathrm{COOH}$ terminus and thus inhibit Grb10 binding. It is also possible that the native Grb10 protein is localized in cellular compartments that are more readily accessible to the insulin receptor than to the IGF-I receptor.

Grb10 binds to the insulin receptor independently of IRS-1 (23) and, therefore, may link the insulin receptor to a novel intracellular pathway. Alternatively, Grb10 may modulate insulin receptor transducing potential, as suggested for Grb-IR, a human protein closely related to $\operatorname{Grb} 10(25,26)$. Three major protein bands are identified by Grb10 specific antibody in Rcells (Fig. $3 A$ ) and other cell types (24). A similar pattern of Grb10 isoforms is seen in NIH3T3 cells and HeLa cells transfected with Grb10 cDNA, indicating that the different molecular species derive from the same DNA sequence (24). In this study, we report the cloning of a previously unknown splice variant of Grb10, that lacks a 25-amino acid region located between the proline-rich and the PH domains. Similarly, Grb-IR and its recently described isoform Grb10/IR-SV1 lack an 80amino acid fragment when compared with the previously reported Grb10, and this divergent region starts exactly at the same point (aa. 117 of Grb10). Although the structures of the Grb10 protein isoforms in cultured cells have not yet been established, it is likely that they derive from alternative splicing and/or the use of more than one of the three potential translation start codons identified in the cDNA (24). It is also possible that posttranslational modification of the Grb10 protein, such as phosphorylation (24), may contribute to the observed heterogeneity. The $\mathrm{COOH}$-terminal SH2 domain is conserved in all of the potential protein isoforms and has $99 \%$ sequence identity in the mouse and human. Based on studies with fragments of Grb10 (23), this portion of the molecule appears to mediate the interaction with insulin receptors. Consistent with this conclusion, we have observed that all of the Grb10 protein isoforms identified in R-IR cells by direct immunoblotting also coprecipitate with the insulin receptor. In future studies, it will be important to define the structures of the Grb10 isoforms and investigate the possibility that they may have distinct roles in insulin signaling.

\section{Acknowledgments}

The authors would like to thank Susan Habinowski and Karen Tendyke for excellent technical assistance, and Sally McCombs and Christina Reith for contribution to this project during summer research internships.

This work was supported by grants to R.J. Smith from the Markey Foundation and the National Institutes of Health (DK43038); to H. Riedel from the Juvenile Diabetes Foundation and the National Science Foundation (MCB-9316997), and by Diabetes and Endocrinology Research Center Grant DK36836. L. Laviola was supported by fellowships from the Mary K. Iacocca Foundation, the Juvenile Dia- betes Foundation, and the Dottorato di Ricerca in Scienze Endocrinologiche e Metaboliche, Universities of Bari and Naples; F. Giorgino was supported by the Mary K. Iacocca Foundation; J.C. Chow by National Institutes of Health Training Grant DK07260; J.A. Baquero by an American Diabetes Association Mentor-based Fellowship (to R.J. Smith); H. Hansen by the Mary K. Iacocca Foundation; and J. Zhu by the Juvenile Diabetes Foundation.

\section{References}

1. Ullrich, A., J.R. Bell, E.Y. Chen, R. Herrera, L.M. Petruzzelli, T.J. Dull, A. Gray, L. Coussens, Y.C. Liao, M. Tsubokawa, et al. 1985. Human insulin receptor and its relationship to the tyrosine kinase family of oncogenes. Nature (Lond.). 313:756-761.

2. Ullrich, A., A. Gray, A.W. Tam, T. Yang-Feng, M. Tsubokawa, C. Collins, W. Henzel, T. Le Bon, S. Kathuria, E. Chen et al. 1986. Insulin-like growth factor I receptor primary structure: comparison with insulin receptor suggests structural determinants that define functional specificity. EMBO (Eur. Mol. Biol. Organ.) J. 5:2503-2512.

3. Abbott, A.M., R. Bueno, M.T. Pedrini, J.M. Murray, and R.J. Smith. 1992. Insulin-like growth factor I receptor gene structure. J. Biol. Chem. 267: 10759-10763.

4. Cheatham, B., and C.R. Kahn. 1995. Insulin action and the insulin signaling network. Endocr. Rev. 16:117-142.

5. LeRoith, D., H. Werner, D. Beitner-Johnson, and C.T. Roberts, Jr. 1995. Molecular and cellular aspects of the insulin-like growth factor I receptor. Endocr. Rev. 16:143-163.

6. Rothenberg, P.L., W.S. Lane, J.M. Backer, M.F. White, and C.R. Kahn. 1991. Purification and partial sequence analysis of pp185, the major cellular substrate of the insulin receptor tyrosine kinase. J. Biol. Chem. 266:8302-8311.

7. Chuang, L.M., M.G. Myers, Jr., G.A. Seidner, M.J. Birnbaum, M.F. White, and C.R. Kahn. 1993. Insulin receptor substrate 1 mediates insulin and insulin-like growth factor I-stimulated maturation of Xenopus oocytes. Proc. Natl. Acad. Sci. USA. 90:5172-5175.

8. Gustafson, T.A., W. He, A. Craparo, C.D. Schaub, and T.J. O'Neill. 1995. Phosphotyrosine-dependent interaction of SHC and insulin receptor substrate 1 with the NPEY motif of the insulin receptor via a novel non-SH2 domain. Mol. Cell. Biol. 15:2500-2508.

9. Craparo, A., T.J. O'Neill, and T.A. Gustafson. 1995. Non-SH2 domains within insulin receptor substrate-1 and SHC mediate their phosphotyrosinedependent interaction with the NPEY motif of the insulin-like growth factor I receptor. J. Biol. Chem. 270:15639-15643.

10. Sun, X.J., L.-M. Wang, Y. Zhang, L. Yenush, M.G. Myers, Jr., E. Glasheen, W.S. Lane, J.H. Pierce, and M.F. White. 1995. Role of IRS-2 in insulin and cytokine signalling. Nature (Lond.). 377:173-177.

11. Patti, M.E., X.J. Sun, J.C. Bruening, E. Araki, M.A. Lipes, M.F. White, and C.R. Kahn. 1995. 4PS/insulin receptor substrate (IRS)-2 is the alternative substrate of the insulin receptor in IRS-1-deficient mice. J. Biol. Chem. 270: 24670-24673.

12. Pelicci, G., L. Lanfrancone, F. Grignani, J. McGlade, F. Cavallo, G. Forni, I. Nicoletti, F. Grignani, T. Pawson, and P.G. Pelicci. 1992. A novel transforming protein (SHC) with an $\mathrm{SH} 2$ domain is implicated in mitogenic signal transduction. Cell. 70:93-104.

13. Ruderman, N., R. Kapeller, M.F. White, and L.C. Cantley. 1990. Activation of phosphatidylinositol 3-kinase by insulin. Proc. Natl. Acad. Sci. USA. 87: 1411-1415.

14. Staubs, P.A., D.R. Reichart, A.R. Saltiel, K.L. Milarski, H. Maegawa, P. Berhanu, J.M. Olefsky, and B.L. Seely. 1994. Localization of the insulin receptor binding sites for the SH2 domain proteins p85, Syp, and GAP. J. Biol. Chem. 269:27186-27192.

15. Seely, B.L., D.R. Reichart, P.A. Staubs, B.H. Jhun, D. Hsu, H. Maegawa, K.L. Milarski, A.R. Saltiel, and J.M. Olefsky. 1995. Localization of the insulin-like growth factor I receptor binding sites for the $\mathrm{SH} 2$ domain proteins p85, Syp, and GTPase activating protein. J. Biol. Chem. 270:19151-19157.

16. Sahal, D., J. Ramachandran, and Y. Fujita-Yamaguchi. 1988. Specificity of tyrosine protein kinases of the structurally related receptors for insulin and insulin-like growth factor I: Tyr-containing synthetic polymers as specific inhibitors or substrates. Arch. Biochem. Biophys. 260:416-426.

17. Xu, B., V.G. Bird, and W.T. Miller. 1995. Substrate specificities of the insulin and insulin-like growth factor receptor tyrosine kinase catalytic domains. J. Biol. Chem. 270:29825-29830.

18. Lammers, R., A. Gray, J. Schlessinger, and A. Ullrich. 1989. Differential signalling potential of insulin- and IGF-I-receptor cytoplasmic domains. EMBO (Eur. Mol. Biol. Organ.) J. 8:1369-1375.

19. Tartare, S., I. Mothe, A. Kowalski-Chauvel, J.-P. Breittmayer, R. Ballotti, and E. Van Obberghen. 1994. Signal transduction by a chimeric insulinlike growth factor-I (IGF-I) receptor having the carboxyl-terminal domain of the insulin receptor. J. Biol. Chem. 269:11449-11455.

20. Miura, M., E. Surmacz, J.-L. Burgaud, and R. Baserga. 1995. Different effects on mitogenesis and transformation of a mutation at tyrosine 1251 of the 
insulin-like growth factor I receptor. J. Biol. Chem. 270:22639-22644.

21. Fields, S., and O. Song. 1989. A novel genetic system to detect proteinprotein interactions. Nature (Lond.). 340:245-246.

22. Bartel, P.L., C. Chien, R. Sternglanz, and S. Fields. 1993. Using the twohybrid system to detect protein-protein interactions. In Cellular Interactions in Development: A Practical Approach. D.A. Hartley, editor. IRL Press, Oxford. 153-179.

23. Hansen, H., U. Svensson, J. Zhu, L. Laviola, F. Giorgino, G. Wolf, R.J. Smith, and H. Riedel. 1996. Interaction between the Grb10 SH2 domain and the insulin receptor carboxyl terminus. J. Biol. Chem. 271:8882-8886.

24. Ooi, J., V. Yajnik, D. Immanuel, M. Gordon, J.J. Moskow, A.M. Buchberg, and B. Margolis. 1995. The cloning of Grb10 reveals a new family of SH2 domain proteins. Oncogene. 10:1621-1630.

25. Liu, F., and R.A. Roth. 1995. Grb-IR: a SH2-domain-containing protein that binds to the insulin receptor and inhibits its function. Proc. Natl. Acad. Sci. USA. 92:10287-10291.

26. O’Neill, T.J., D.W. Rose, T.S. Pillay, K. Hotta, J.M. Olefsky, and T.A. Gustafson. 1996. Interaction of a GRB-IR splice variant (a human GRB10 homolog) with the insulin and insulin-like growth factor I receptors. J. Biol. Chem. 271:22506-22513.

27. Vojtek, A.B., S.M. Hollenberg, and J.A. Cooper. 1993. Mammalian Ras interacts directly with the serine/threonine kinase Raf. Cell. 74:205-214.

28. Hollenberg, S.M., R. Sternglanz, P.F. Cheng, and H. Weintraub. 1995. Identification of a new family of tissue-specific basic helix-loop-helix proteins with a two-hybrid system. Mol. Cell. Biol. 15:3813-3822.

29. Schiestl, R.H., and R.D. Gietz. 1989. High efficiency transformation of intact yeast cells using single stranded nucleic acids as a carrier. Curr. Genet. 16: 339-346.

30. Hill, J., K.A. Donald, and D.E. Griffiths. 1991. DMSO-enhanced whole cell yeast transformation. Nucleic Acids Res. 19:5791.

31. Chomczynski, P., and N. Sacchi. 1987. Single step method of RNA isolation by acid guanidinium thiocyanate-phenol-chloroform extraction. Anal. Biochem. 162:156-159.

32. Sell, C., M. Rubini, R. Rubin, J.-P. Liu, A. Efstratiadis, and R. Baserga. 1993. Simian virus 40 large tumor antigen is unable to transform mouse embryonic fibroblasts lacking type 1 insulin-like growth factor receptor. Proc. Natl. Acad. Sci. USA. 90:11217-11221.

33. Sell, C., G. Dumenil, C. Deveaud, M. Miura, D. Coppola, T. DeAngelis, R. Rubin, A. Efstratiadis, and R. Baserga. 1994. Effect of a null mutation of the insulin-like growth factor I receptor gene on growth and transformation of mouse embryo fibroblasts. Mol. Cell. Biol. 14:3604-3612.

34. Liu, J.-P., J. Baker, A.S. Perkins, E.J. Robertson, and A. Efstratiadis. 1993. Mice carrying null mutations of the genes encoding insulin-like growth factor I (Igf-1) and type 1 IGF receptor (Igf1r). Cell. 75:59-72.
35. Baker, J., J.-P. Liu, E.J. Robertson, and A. Efstratiadis. 1993. Role of insulin-like growth factors in embryonic and postnatal growth. Cell. 75:73-82.

36. Coppola, D., A. Ferber, M. Miura, C. Sell, C. D'Ambrosio, R. Rubin, and R. Baserga. 1994. A functional insulin-like growth factor I receptor is required for the mitogenic and transforming activities of the epidermal growth factor receptor. Mol. Cell. Biol. 14:4588-4595.

37. Giorgino, F., J.H. Chen, and R.J. Smith. 1992. Changes in tyrosine phosphorylation of insulin receptors and a 170,000 molecular weight nonreceptor protein in vivo in skeletal muscle of streptozotocin-induced diabetic rats: effects of insulin and glucose. Endocrinology. 130:1433-1444.

38. Pons, S., T. Asano, E. Glasheen, M. Miralpeix, Y. Zhang, T.L. Fisher, M.G. Myers, Jr., X.J. Sun, and M.F. White. 1995. The structure and function of p55PIK reveal a new regulatory subunit for phosphatidylinositol 3-kinase. Mol. Cell. Biol. 15:4453-4465.

39. Mount, S.M. 1982. A catalogue of splice junction sequences. Nucleic Acids Res. 10:459-472.

40. Margolis, B. 1995. The GRB family of SH2 domain proteins. Prog. Biophys. Mol. Biol. 62:223-244.

41. Sun, X.J., P. Rothenberg, C.R. Kahn, J.M. Baker, E. Araki, P.A. Wilden, D.A. Cahill, B.J. Goldstein, and M.F. White. 1991. The structure of the insulin receptor substrate IRS-1 defines a unique signal transduction protein. Nature (Lond.). 352:73-77.

42. Pandey, A., H. Duan, P.P. Di Fiore, and V.M. Dixit. 1995. The Ret receptor protein tyrosine kinase associates with the $\mathrm{SH} 2$-containing adapter protein Grb10. J. Biol. Chem. 270:21461-21463.

43. Siddle, K., M.A. Soos, C.E. Field, and B.T. Nave. 1994. Hybrid and atypical insulin/insulin-like growth factor I receptors. Horm. Res. 41(Suppl. 2): 56-64.

44. Frattali, A.L., and J.E. Pessin. 1993. Relationship between alpha subunit ligand occupancy and beta subunit autophosphorylation in insulin/insulin-like growth factor-1 hybrid receptors. J. Biol. Chem. 268:7393-7400.

45. Allen, J.B., M.W. Walberg, M.C. Edwards, and S.J. Elledge. 1995. Finding prospective partners in the library: the two-hybrid system and phage display find a match. Trends Biochem. Sci. 20:511-516.

46. Beitner-Johnson, D., and D. LeRoith. 1995. Insulin-like growth factor-I stimulates tyrosine phosphorylation of endogenous c-Crk. J. Biol. Chem. 270 5187-5190.

47. Thies, R.S., A. Ullrich, and D.A. McClain. 1989. Augmented mitogenesis and impaired metabolic signaling mediated by a truncated insulin receptor. J. Biol. Chem. 264:12820-12825.

48. Takata, Y., N.J. Webster, and J.M. Olefsky. 1991. Mutation of the two carboxyl-terminal tyrosines results in an insulin receptor with normal metabolic signaling but enhanced mitogenic signaling properties. J. Biol. Chem. 266:91359139. 